\title{
Key performance indicators of disaster preparedness: a case study of a tsunami disaster
}

\author{
Reinny Patrisina ${ }^{1,2,}{ }^{*}$, Faradissa Emetia $^{1}$, Nikorn Sirivongpaisal ${ }^{2}$, Sakesun Suthummanon ${ }^{2}$, Alfadhlani Alfadhlani ${ }^{1}$, \\ and Dicky Fatrias ${ }^{1}$
}

${ }^{1}$ Universitas Andalas, Industrial Engineering Department, 25163 Padang, Indonesia

${ }^{2}$ Prince of Songkla University, Industrial Engineering Department, 92110 Hatyai, Thailand

\begin{abstract}
Disaster impacts on human life not only in economic sector but also social, culture, and environment. In order to minimize the disaster risk, it is expected all elements who exposed to the forthcoming disaster make a good disaster preparedness then they will be resilience toward the disaster. Since individual as one of disaster stakeholder who will face a disaster directly, it is expected that they will participate actively in disaster reduction efforts. This study is aimed to design key performance indicators for measuring the disaster preparedness level of an individual. Using the Delphi method, it is obtained 14 indicators of three critical factors identified. The preparedness level of an individual against a disaster is plotted in 2-dimension matrix (awareness \& attitude versus actions taken). The indicators are designed for assessing disaster preparedness of people who live in a tsunami disaster prone area. The indicators can be used by the government to assess the preparedness level of their citizens. Moreover, the indicators will be helpful for government in developing disaster preparedness program to improve people resilience against disaster.
\end{abstract}

\section{Introduction}

The disaster has not only cause of human loss but also effect to economic, social, and environment sectors. According to EM-DAT data [1], between 2006-2015, the natural disaster caused 1.4 trillion USD of economic losses, 1.9 billion of affected people, and 0.7 million of death. Looking at the impact of disasters, to hazardprone areas requires an approach for reducing disaster risks. It can be obtained by implementing disaster management through a continuous cycle of four phases: mitigation, preparedness, response, and recovery [2].

Especially for an area that has identified threatening by disaster hazards, the government should have an understanding regarding disaster risks that they will face. By understanding the risks, they can develop strategies to improve city resilience against a disaster. At first, they are supposed to perform a pre-disaster risk assessment for evaluating and knowing what prevention and mitigation, preparedness and response program that are significant for reducing disaster risks in their areas [3]. In case of mitigation efforts still can't eliminate the disaster, preparedness against the disaster may save lives and alleviate people suffering through the development of emergency plans for performing an effective and efficient response and recovery, translation of the plans shortly, and continuous public awareness about hazards and risks [4].
Many researchers studied how to assess preparedness against disaster. But there is still no consensus which indicators can be used to measure city resilience [5]. People or community disaster preparedness have a significant contribution to city resilience index. People who live in a disaster area will be the first to experience supposing an event strikes their area. So, they will be the first ones who get affected and usually the last ones to recover in a disaster. As the main actor, they are expected to participate actively in disaster risk reduction efforts. A readiness to respond a disaster will increase their resilience as well as decrease their vulnerability [6].

To measure whether citizens living in prone-area have good preparation for the future disaster or not, it is not enough to assess them only through their knowledge relating to the future disaster. It could be that they have a good knowledge regarding the disaster, but it is not guaranty that they can save during and after the disaster. It is required to measure the concrete things that they have done to make their self and their family survive during and after a disaster.

Most disaster preparedness indicators of previous studies [7-9] focused on common factors. Those factors include knowledge relating potential disasters, disaster preparedness plan, warning system, and resource mobilization. While research conducted by [10], adding one more factor to assess that is policy and rule. Most statements used stressed on the knowledge regarding all the factors and how to save himself during a disaster. It

*Corresponding author: rpatrisina@ft.unand.ac.id 
still can't measure whether affected people have done a concrete thing for facing a disaster or not. However, surviving after a disaster is also important since people can save during a disaster but it is not guaranty that they will also still save at post-disaster. It is possible that the disaster can shut down service that families depend on it such health care, stores, and market while in most situations, relief aids will come after 72 hours [11]. Thus, they are supposed to prepare on it at least for the first three days after the event. In addition, people are who will face a disaster directly and personally.

This study is aimed to design key performance indicators for measuring disaster preparedness at the community level. These indicators will provide information regarding critical factors that have become concerning by affected people and government in developing disaster preparedness program for communities to improve people resilience against disaster. The indicators are designed for assessing disaster preparedness of people who live in a tsunami disaster prone area. Since most people die in disasters occurred during the last decade are contributed by an earthquake and tsunami disaster [1].

\section{Theory and method}

Resilience is the ability to resist stress, survive, adapt, and get over from a crisis and move on swiftly [12]. Resilience means the capability of a system or component of the system (such as individual and household) to withstand and revert from the event [13].

Communities who have a good understanding regarding the future disaster that threatens them will have good disaster preparedness and making them resilience to a disaster. In case a disaster strikes their region, the number of human losses as well as economic losses can be minimized. Moreover, they just need a shorter time to recover from the event and back to normalcy immediately.

Previous studies used the same indicators for measuring a level of preparedness for each disaster stakeholder. Perhaps some indicators are appropriate to all stakeholders but there are indicators that only can answer by certain stakeholders. For example, we can't ask communities regarding government policies or how the government will perform disaster response after the event take place, only the government is reliable to answer it. Otherwise, we also can't ask the government with questions that it is supposed to be answered by communities since there may have different perception between them. The government may claim that the people have known where they will go in case a disaster occurs since the government has installed an evacuation route map and signs in the red zone. In the field, perhaps we still can find someone who said I do not know where I will go in case the event strikes the area. Thus, though the government has done something for their people, the people may not absorb it well. So, certain stakeholders may require specific key performance indicators which are different from the others.
Assessing preparedness against a disaster is a complicated process since each disaster has its characteristics and different disaster stakeholders (government, individual, households, private sectors, public facilities, non-government organization) which require different indicators for measuring their resilience against disaster.

This study was conducted in four steps, as follows:

1) Study critical factors of disaster preparedness: this study would use previous literature and theoretical constructs to more fully understand what factors that have significant effects in measuring individual preparedness against a disaster.

2) Developed indicators of disaster preparedness: according to the current study conducted, we propose a framework where indicators can be examined and developed. This step involves disaster stakeholders through Delphi Methods. The disaster stakeholders are selected from government, academics, and experts who involve in the non-government organization and have experiences in disaster management for more than five years.

3) Developing a model for determining individual disaster preparedness index (IPI): this index will give a broad indication of individual preparedness toward a disaster. The higher the preparedness score, the more resilience individual against a disaster.

4) Revising framework and instrument based on field testing.

\section{Results and discussion}

\subsection{Critical factors of disaster preparedness}

Awareness of their surrounding by knowing that they live in a disaster area is not enough to say that the disaster vulnerable people will be resilience against a disaster. Since to be prepared requires people to think and understand the risk that they face, their household needs and how they and their families live every day, and how they want to live after a disaster occurs when services shut down following a disaster, for days or weeks [11].

As mentioned in Sendai Framework Disaster Risk Reduction (SFDRR) 2015-2030 in priority 4, it is required to enhance preparedness for effective response and to build back better in recovery, rehabilitation, and reconstruction [3]. Then, disaster preparedness is aimed to make affected people save in a disaster and at postdisaster then they can build back better to normalcy by shorter time. The disaster vulnerable people are required to have knowledge relating the future disasters and an understanding regarding the hazards. By knowing and understand what risks they will face then, they have a willingness to prepare for the disasters by taking concrete actions in term of disaster preparedness and having a continuous awareness relating disaster hazards and its risks. They are encouraged to make a preparedness plan for himself and his family and have an ability to mobilize the plan quickly and effectively in case a disaster occurs. 
Critical factors are listed in the previous study to be determined by identified experts through the Delphi method. Table 1 provides list indicators for measuring people preparedness toward a tsunami disaster. They are identified as being knowledge (understanding of a disaster and disaster awareness), disaster emergency plan (understanding preparedness and doing preparedness actions), information and communication.

\subsection{Indicators of disaster preparedness}

Identifying pre-disaster preparedness indicators is critical in analysing individual disaster resilience. Through the Delphi method, a collaborative and consensus-based process among selected experts in disaster management field, the individual preparedness measurement will be determined and weighted. Preparedness against a disaster of an individual can be explained as a collaboration of knowledge, disaster emergency plan, and information and communication.

Three critical factors identified are elaborated to be 14 indicators represented significant factors to make people fully prepared toward disasters and become resilience. The factor of knowledge, disaster emergency plan, and information and communication are measured using six, five, and three indicators, respectively, as shown in Table 1.

Table 1. Key performance indicators of individual preparedness toward a disaster

\begin{tabular}{|c|c|}
\hline Critical factors & Indicators \\
\hline Knowledge & $\begin{array}{l}\text { 1) Disaster characteristics } \\
\text { 2) early warning system } \\
\text { 3) evacuation facility } \\
\text { 4) evacuation route } \\
\text { 5) disaster experience and } \\
\text { 6) disaster simulation/drill exercise. }\end{array}$ \\
\hline $\begin{array}{c}\text { Disaster } \\
\text { emergency plan }\end{array}$ & $\begin{array}{l}\text { 1) Protecting assets } \\
\text { 2) self and family evacuation } \\
\text { 3) engagement with a family } \\
\text { 4) communication and } \\
\text { 5) supplies and live stocks. }\end{array}$ \\
\hline $\begin{array}{l}\text { Information and } \\
\text { communication }\end{array}$ & $\begin{array}{l}\text { 1) Source of information } \\
\text { 2) communication with communities and } \\
\text { 3) asking and getting help. }\end{array}$ \\
\hline
\end{tabular}

\subsubsection{Knowledge}

Knowledge of the citizens living in the prone area toward the threatened disaster is the first aspect that will become concerning by disaster stakeholders to improve disaster preparedness level. It is expected that they have known well regarding the future event and having understanding and awareness about the disaster. The disaster knowledge of the exposed people is measured using six indicators: the characteristic of the disaster, early warning system, evacuation facilities such as vertical shelters, tsunami evacuation map, and route, disaster experience, disaster simulation/disaster drill exercise.

\subsubsection{Disaster emergency plan}

By having a knowledge regarding the forthcoming disaster, it is not enough to justify that the exposed people will survive in and after the event. Affected people are encouraged to make a preparedness plan for himself and his family and have an ability to mobilise the plan quickly and effectively in case a disaster occurs. The affected people should have an understanding regarding the hazards, what risks they will face then, they have to understand the significance of preparedness to be saved during and after the disaster attacks and have a willingness to prepare for the disasters by taking concrete actions. So, it is required for them to develop an emergency plan and making a proactive action upon disaster preparedness. The preparedness plan includes the plan to cover their assets by ensuring their property, self, and family evacuation plan, engagement with a family, communication, and supplies and lives stocks.

\subsubsection{Information and communication}

In case a disaster occurs, they know how to get valid information, sharing them with their communities, and asking and getting help.

\subsection{Individual preparedness level}

Furthermore, the results of the assessment will be calculated and analyzed to know the level of individual disaster preparedness.

The level of individual preparedness against a disaster will be plotted in a matrix such used by [4]. Fig. 1. shows the matrix for assessing disaster preparedness level.

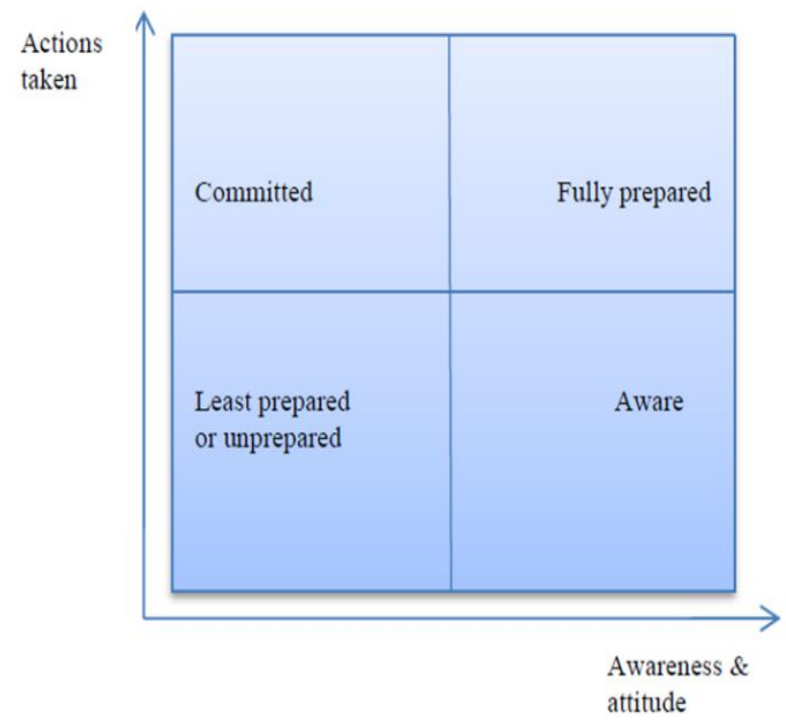

Fig. 1. Matrix for assessing disaster preparedness level (Adopted from [4])

Fig. 1. shows that the matrix is divided into four quadrants. Individuals who locate in the first quadrant (low awareness \& attitude and low actions are taken) have the lowest level of preparedness regarding the 
disaster. They do nothing or a few things for preparing their selves toward a disaster then they are categorized as least prepared or unprepared. On contrary, individuals whose score in the third quadrant (high awareness \& attitude and high actions are taken) reaches the highest disaster preparedness level (fully prepared) and be the most resilience against a disaster compared to individuals in the other three quadrants. Hopefully, they will save during a disaster and they can recover promptly. While individuals who position in the second (high awareness \& attitude and low actions are taken) are categorized as aware and the fourth quadrant (low awareness \& attitude and high actions are taken) are categorized as committed.

\section{Conclusion}

Designing key performance indicators of disaster preparedness is critical in analyzing disaster resilience. Knowing which factors that play significant roles, it will help people living in a prone-area to focus on their preparedness toward a disaster. This study is aimed to design key performance indicators of disaster preparedness at the community level. Using the Delphi method, it has been identified 14 indicators from three critical factors identified encompassing knowledge, disaster emergency plan, and information and communication. The developed indicators can be used to measure whether affected people have done concrete things to prepared against a disaster or not then they can survive during and after a disaster. Then preparedness level of an individual against a disaster is plotted in 2dimension of the matrix. The horizontal axis is recognized as awareness and attitude, while the vertical one is stated as actions taken. The matrix is divided into four quadrants: least prepared/unprepared (quadrant 1), commit (quadrant 2), fully prepared (quadrant 3), and aware (quadrant 4). An individual who locates in the first quadrant has the lowest preparedness level toward the disaster that threats their life. On the contrary, individuals whose score in the third quadrant reaches the highest disaster preparedness level and become the most resilience against a disaster compared to individuals in the other three quadrants. It will be helpful government to develop disaster preparedness programs to improve people resilience.

For the future research, the developed indicators can be tested on people who live in a tsunami prone area.

We would like to thank the Ministry of Research and Education, Republic of Indonesia, and Industrial Engineering Department of Universitas Andalas for their supported research fund. We also would like to thank District Disaster Management Agency of Padang (BPBD Padang) and our friends in Disaster Risk Reduction Indonesia (DRRI) Padang for useful discussion and sharing knowledge.

\section{References}

1. IFRC, World Disaster Report, Resilience: saving lives today, investing for tomorrow (IFRC, Switzerland, 2016)
2. N. Altay and W. G. Green III, Eur J Oper Res, 175, 475-493 (2006)

3. UNISDR, Sendai framework for disaster risk reduction 2015-2030 (UNISDR, New York, 2015)

4. M. K. Raneses, A. Chang-Richards, J. Richards, and J. Bubb, Procedia Eng, 212, 419-426 (2018)

5. T. Winderl, Disaster Resilience Measurement: Stocktaking of ongoing efforts in developing systems for measuring resilience (UNISDR, Switzerland, 2014)

6. J. C. Gaillard, J. Int. Dev, 22, 218-232 (2010)

7. A. C. Nugroho, Community preparedness study in anticipating earthquake and tsunami disasters in South Nias [ID] (MPBI-UNESCO, Jakarta, 2007)

8. BNPB, Pilot survey of knowledge, attitude, and practice (KAP): disaster preparedness in Padang City 2013 (BNPB, Jakarta, 2013)

9. BPBD Padang, Final report: survey of community preparedness of Padang [ID] (BPBD Padang, Padang, 2017).

10. LIPI - UNESCO, Community preparedness study in anticipating earthquake and tsunami disaster [ID] (LIPI-UNESCO, Jakarta, 2006)

11. NCDP, The NCDP model for disaster preparedness (Columbia University, New York, 2018)

12. I. Wagner and P. Breil, Ecohydrol Hydrobiol, 13, 113-134 (2013)

13. B. Allenby and J. Fink, Sci, 309, 1034-1036 (2005). 